\title{
Hospital service quality measurement models: patients from Asia, Europe, Australia and America
}

Natcha Thawesaengskulthai, Patcharin Wongrukmit and Jens Jörn Dahlgaard

\author{
Linköping University Post Print
}

\section{Tweet}

N.B.: When citing this work, cite the original article.

This is an electronic version of an article published in:

Natcha Thawesaengskulthai, Patcharin Wongrukmit and Jens Jörn Dahlgaard, Hospital service quality measurement models: patients from Asia, Europe, Australia and America, 2015, Total quality management and business excellence (Online), (26), 9-10, 1029-1041.

Total quality management and business excellence (Online) is available online at informaworldTM:

http://dx.doi.org/10.1080/14783363.2015.1068596

Copyright: Taylor \& Francis (Routledge): SSH Titles

http://www.routledge.com/

Postprint available at: Linköping University Electronic Press

http://urn.kb.se/resolve?urn=urn:nbn:se:liu:diva-122202 


\author{
Hospital Service Quality Measurement Models: \\ Patients from Asia, Europe, Australia, and America \\ Natcha Thawesaengskulthai ${ }^{* a}$ (Natcha.T@chula.ac.th) \\ Department of Industrial Engineering, Faculty of Engineering, \\ Chulalongkorn University, Thailand \\ Patcharin Wongrukmit ${ }^{\mathrm{b}}$ (Patcharin.Won@Student.chula.ac.th) \\ Technopreneurship and Innovation Management, Graduate School, \\ Chulalongkorn University, Thailand \\ Jens J. Dahlgaard ${ }^{c}$ (Jens.jorn.dahlgaard@liu.se) \\ Division of Quality Technology and Management, \\ Linköping University, Linköping, Sweden
}

This study explores how service quality in hospitals is perceived and measured among different groups of patients from four major continents (i.e. Asia, Europe, Australia and North America) who came to receive medical services in Thailand. Using stratified random sampling, data were collected from 2189 patients from 80 countries and four continents at six hospitals which provide healthcare services to international patients in Thailand. Four different models of measuring service quality based on different continents were developed with different numbers of quality dimensions and also a variation in the number of quality attributes. Asian patients provided a four dimension model with 20 items; while a two-dimension model with 16 items was identified for European patients. Australian patients also revealed a two-dimension model but with 22 items, while patients from America provided a three-dimension model, also with 17 items. The study reveals that the development of service quality measurement models should not only consider context-specific items such as size and location, but should also include the nationality and demographic of the patient population. The findings also support that service quality has a significant impact on service satisfaction and the retention level of customers at the hospital. The concluded frameworks may guide healthcare providers to deliver better quality healthcare services and to sustain competitiveness.

Keywords: Service Quality Measurement, Hospital Service Quality, Structural Equation Models

\footnotetext{
* Corresponding author. Email: natcha.t@ chula.ac.th
} 


\section{Introduction}

Global competition is emerging in the healthcare industry. The growth of the senior citizen population and a growing focus on health have dynamically increased health needs within the general population. The new era of globalisation in healthcare arrived in the first decade of the twenty-first century when middle-class patients began travelling from developed countries to developing countries with emerging economies to avoid treatment delays, long waiting lists or simply high costs for elective surgery (Herrick, 2007).

In Southeast Asia, the health sector is expanding rapidly, attributable to the rapid growth of the private sector and notably to medical tourism, the organised travel outside the country of residence for the purpose of receiving medical care. This is a clear trend in Southeast Asia, especially in Thailand, Singapore and Malaysia, the main regional hubs for medical tourism, where there is strong support from governments to increase medical tourist inflows (Pocock \& Phua, 2011). Medical tourism is driven by the private sector, and in Thailand, the number of private hospitals is about $30 \%$ of the total number of hospitals from the report of a private hospital survey by National Statistical Office of Thailand for 2012. The steady growth of private sector hospitals has catered for medical tourists to access their services. When the industry structure changes, the role patients play in defining what quality means has become important. As a result, service quality has become a critical, competitive strategy consideration for healthcare organisations.

Although there is a large body of studies, including models and theories of healthcare consumer behaviour, most of the past studies were conducted within the US healthcare context. Consequently, the stability and applicability of past findings across different national/cultural settings remain largely untested (Choi, Cho, Lee, Lee, \& Kim, 2004). Moreover in the context of medical tourist destination, it would be interesting to see if service quality is perceived differently by medical tourists who travel from all over the world to receive healthcare services in the same medical destination. From this perspective, the purposes of this study are (1) to propose a model showing the functional relationships among patient

satisfaction and related variables and (2) to examine the effects of this conceptualisation of healthcare service quality on satisfaction and behavioural intentions. 


\section{Literature review and conceptual development}

\subsection{Measuring Service Quality}

Over the past two decades, research on service quality has grown extensively and substantially. The discriminatory characteristics of services and products are intangibility, inseparability, heterogeneity and perishability. These characteristics make services more difficult to evaluate than products, which typically can be inspected and evaluated for quality before the purchase takes place (Zeithaml, Parasuraman, \& Berry, 1985). Service quality has been perhaps the most explored topic in services marketing. Past research has linked service quality to customer satisfaction (Cronin \& Taylor, 1992; McAlexander, Kaldenberg, \& Koenig, 1994), value and satisfaction (Cronin, Brady, \& Hult, 2000) and behavioural intention (Headley \& Miller, 1993; Zeithaml, Berry, \& Parasuraman, 1996). There has been no consensus among researchers regarding whether service quality perceptions should be measured or not; it is generally agreed that service quality is a multidimensional, higher order construct (Gro" nroos, 1984; Parasuraman, Zeithaml, \& Berry, 1988). Gro“nroos (1984), for example, suggests that service quality comprises two distinct components: the technical aspect, or WHAT is provided, and the functional aspect, or HOW the service is provided. As well as providing a foundation for the development of service quality scale, SERVQUAL provides the merging of five dimensions: tangibility, reliability, assurance, responsiveness and empathy (Parasuraman et al.,1988). Finally, Brady and Cronin (2001) propose that service quality is composed of the dimensions of interpersonal quality, outcome quality and environmental quality. Babakus and Boller (1992) state that service quality may be complex and multidimensional for some services and one-dimensional for others.

\subsection{Health Care Service Quality Measurement}

In the healthcare literature, several conceptual frameworks for evaluating the quality of care have been proposed. In the traditional medical approach, the primary focuses of healthcare centre on increasing the probability of desirable healthcare outcomes, given the state of knowledge and technology. Studies differentiate between two primary domains of managing healthcare quality: process and outcome of care (Donabedian, 1978, 1988). The application of SERVQUAL to health service quality analysis has been widely used in many countries such as the USA, Singapore, Malaysia, Jordan, Iran and Thailand (Alrubaiee, \& Alkaa'ida 2011; Babakus \& Mangold, 1992; Lim \& Tang, 2000; Nekoei-Moghadam \& Amiresmaili, 2011; Suki, Lian, \& Suki, 2011; Untachai, 2013).

Pai and Chary (2013) reviewed hospital service quality studies and found that SERVQUAL/ modified SERVQUAL has been used as an instrument in $49 \%$ of studies. The number of quality dimensions varies from researcher to researcher. For example, Reidenbach and Sandifer-Smallwood's (1990) study reduced 10 dimensions, that is, the original SERVQUAL, to seven; Lim and Tang (2000) added 'accessibility' and 'affordability' dimensions to their study in Singapore; Lee, Delene, Bunda, and Kim (2000) proposed two additional dimensions, that is, 'medical services' and 'professionalism'.

Apart from the SERVQUAL-based models, the Choi, Lee, Kim, and Lee (2005) study in Korea provided a four-factor structure: physician concern, staff concern, convenience of care process and tangibles. In India, several studies have been conducted to propose a service quality measurement model and quality dimensions, such as nursing care, physician care, infrastructure, environment, outcome, medical services, discharge process, administrative/operation and social responsibility (Aagja \& Garg, 2010; Chahal \& Kumari, 2010; D’Souza \& Sequeira, 2012). A Taiwan study used a two-dimension service quality model: competence and interpersonal quality (Chen \& Cheng, 2010), whereas for a study in Japan, functional and technical quality were used (Eleuch, 2011). A service quality measurement in Thailand considered communication, responsiveness, courtesy, cost and cleanliness to be relevant (Hasin, Seeluangsawat, \& Shareef, 2001). 
Health service quality is a multidimensional construct. A comparison of the healthcare dimensions identified with those evident in the marketing literature indicates a considerable overlap, that is, both literatures identify the importance of the technical, functional, environment, administrative and personnel dimensions of the service experience. The application of SERVQUAL in health service quality analysis showed that intangible elements tend to be more influential than tangible ones (Kara, Lonial, Tarim, \& Zaim, 2005), although one should always consider adapting the scale in specific situations. It is noticeable that the majority of studies about service quality in healthcare do not provide a comprehensive outcome element, which could be due to difficulties in measuring the results in healthcare service quality. The problem with measuring healthcare results, according to Choi et al. (2005), could be a consequence of the very long period of time between the moment when the service is provided and the occurrence of results.

\subsection{Satisfaction}

Consumer satisfaction is a fundamental determinant in maintaining long-term customer behaviour (Zeithaml et al., 1996). There is empirical evidence supporting this causal linkage between healthcare service quality and patient satisfaction (Bowers, Swan, \& Koehler, 1994; Reidenbach \& Sandifer-Smallwood, 1990). For healthcare providers, consumer satisfaction leads to favourable results, such as higher rates of patient retention, positive word of mouth and higher profits (Peyrot, Philip, \& Schnapf, 1993). In other words, the more satisfied customers are, the greater the customer retention and willingness to recommend (Zeithaml et al., 1996). Patient satisfaction also influences the rate of patient compliance with physician advice and requests (Calnan, 1988). Thus, satisfaction actually affects the outcome of medical practices. For these reasons, patient satisfaction assessment has become an integral part of healthcare organisations' strategic processes.

The first hypothesis of this study pertains to the causal link between service quality and patient satisfaction. Based on the predominant view in the literature, the following hypothesis is formulated:

\section{H1: Perceived service quality has a significant relationship with patient satisfaction.}

Zeithaml et al. (1996) define behavioural intention as a signal of whether customers will remain or exit the relationship with the service provider. Furthermore, their study identified two dimensions to measure behavioural intention: favourable and unfavourable. Favourable intentions means the customers will convey a positive word of mouth, repurchase intention and loyalty. Repurchase intention is defined as being when customers maintain the relationship with their service provider; word-of-mouth communication is defined as being when customers will inform their friends, relatives and others about their positive experience. Evidence for the significant impact of satisfaction on behavioural intention comes from a wide variety of service industries, including healthcare (Bitner, 1990; Cronin \& Taylor, 1992). Therefore, the following hypothesis is formulated:

\section{H2: Patient satisfaction has a significant effect on patients' behavioural intentions.}

\section{Methodology}

\subsection{Subject and data collection}

The healthcare industry in Thailand is the context for this research. Using stratified random sampling, data were specifically collected from patients who had received services in the previous year from six hospitals which provide services to international patients. The study was conducted in the largest hospital group in the Asia Pacific region and the selected hospitals located in attractive tourist destination cities, that is, Bangkok, Phuket and Hua Hin. All of these samples were derived from each hospital's database and 
represented the total number of patients attending the hospital during the previous 12 months. The questionnaire surveys were mailed to all patients in the sample. In total, 3000 questionnaires were mailed and 2187 usable surveys were returned within two weeks during March 2014.

\subsection{Scale development}

\subsubsection{Qualitative study}

Extra effort was put into the development of measurement items for this study. Especially for the service quality items, the process took into consideration the past studies' recommendations that the scale be unique to the specific service situation being considered, and that the number of service quality dimensions may be a function of the particular service industry (Babakus \& Boller, 1992; Carman, 2000).

We began by investigating commonly cited primary dimensions of service quality in the marketing literature, as outlined in the previous section. Through this process, we identified four primary dimensions that reflect service quality perceptions.

Service facility, which comprises a complex mix of environmental features and other supporting elements of the core service, is an added value to a customer's use of a service (Bitner, 1990; Brady \& Cronin, 2001). As services are produced, distributed and consumed in the interaction between a service provider and a customer, the personnel involved are crucial to the customer's ultimate perception of the service provider's performance.

The second service personnel quality reflects the relationship developed between a service provider and a user.

The third dimension is how service professionals' quality reflects the expertise, professionalism and competency of a service provider in delivering a service.

The final primary dimension we identified is service performance as an output element of the core service which meets a customer's expectation (Brady \& Cronin, 2001; Carman, 2000).

The initial pool of items selected for different dimensions were gathered, in cooperation with 31 experts during hospital service quality interviews, using the Delphi technique. In the third round of study, experts provided rating scores of important items and confirmed quality dimensions which resulted in a total of five primary dimensions; the fifth dimension was purpose as a service product quality. This dimension identified core service products in providing healthcare services in order to meet patients' needs; some items were relocated from the other dimensions and others introduced in this phase. Several items were removed from the item pool and on this basis, a refined pool of 48 items was retained. Therefore, at the conclusion of this process, there were 48 items spread over five dimensions - service facility, service personnel, service professional, service performance and service product.

\subsubsection{Quantitative study}

The questionnaire consists of two sections on hospital service quality: demographic profile and patient perception on hospital service quality. A 10-point Likert-type scale was chosen in this study. Rose, Uli, Abdul, and $\mathrm{Ng}$ (2004) found that patients were more used to rating things based on a scale of 100, but that shrinking the scale to 10 seemed to cause little difficulty to them. Moreover, a 10-point Likert scale provides better explanation about variance than a narrower scale (e.g. 5, 7 or 9) which gives a low level of inter-correlation and only limited variance. Respondents were asked to indicate their agreement level on a 10- point Likert scale, ranging from strongly disagree (1) to strongly agree (10). The survey instrument was tested with a pilot sample of 30 patients. The Cronbach alpha result from the pilot test is 0.98. 


\section{Analysis and result}

\subsection{Sample statistic}

A valid return rate of $45.6 \%$ was achieved. The total respondents came from 80 countries which represented four continents; the numbers for each group are 446 Asians, 891 Europeans, 388 Americans and 454 Australians. The characteristics of the respondents were that $52.9 \%$ were male, $47.1 \%$ were female and $35.9 \%$ were over 54 years old. Most respondents had chosen to obtain service in their particular hospital by themselves (71.6\%). The purpose of coming to Thailand for 35.9\% was for a holiday, and $58 \%$ took responsibility for their own finances for the cost of services. A summary of the sampling demographic is shown in Table 1.

\subsection{Measure analysis}

The analysis involved three steps. The first was to explore factors and identify groups of factors by using exploratory factor analysis. The second was to confirm the factor structure of measurement items tapping into service quality. The third step investigated the relationship between the endogenous latent variables (i.e. personnel, professional, product and facility) and the exogenous overall variables (i.e. service quality and behaviour intention). The measurement and structural models were tested using the IBM SPSS AMOS V22 structural equation analysis package. The maximum likelihood method of estimation was utilised to analyse the data.

Table 1: Sample demographic data

\begin{tabular}{|lccccc|}
\hline Characteristics & Asia & Europe & America & Australia & Total \\
\hline Number in each continent & 36 & 33 & 9 & 2 & 80 \\
& & & & & \\
\hline Gender & & & & & \\
\hline Male & $57.7 \%$ & $59.6 \%$ & $52.7 \%$ & $36.9 \%$ & $52.9 \%$ \\
\hline Female & $42.3 \%$ & $40.4 \%$ & $47.3 \%$ & $63.1 \%$ & $47.1 \%$ \\
\hline Age & & & & \\
\hline$<25$ years & $6.9 \%$ & $3.7 \%$ & $3.7 \%$ & $10.7 \%$ & $5.9 \%$ \\
\hline $25-34$ years & $23.1 \%$ & $12.3 \%$ & $14.0 \%$ & $18.5 \%$ & $15.9 \%$ \\
\hline $35-44$ years & $35.8 \%$ & $19.9 \%$ & $14.6 \%$ & $18.3 \%$ & $21.4 \%$ \\
\hline $45-54$ years & $19.9 \%$ & $24.4 \%$ & $18.6 \%$ & $17.4 \%$ & $21.0 \%$ \\
\hline$>54$ years & $14.2 \%$ & $39.7 \%$ & $49.0 \%$ & $35.2 \%$ & $35.9 \%$ \\
\hline Who selected obtaining the service in this hospital? & & & \\
\hline Myself & $67.4 \%$ & $72.9 \%$ & $76.6 \%$ & $68.4 \%$ & $71.6 \%$ \\
\hline Third party payer & $10.1 \%$ & $11.4 \%$ & $7.1 \%$ & $17.8 \%$ & $11.9 \%$ \\
\hline Relative/Family member & $16.4 \%$ & $8.2 \%$ & $5.7 \%$ & $4.5 \%$ & $8.4 \%$ \\
\hline $\begin{array}{l}\text { Doctor/Nurse from Hotel, } \\
\text { Primary Care, Airport etc. }\end{array}$ & $1.7 \%$ & $4.2 \%$ & $6.3 \%$ & $5.3 \%$ & $4.4 \%$ \\
\hline Friend & $2.6 \%$ & & & $2.0 \%$ \\
\hline Other & $1.7 \%$ & $1.5 \%$ & $1.4 \%$ & $2.0 \%$ & $1.7 \%$ \\
\hline The purpose of coming to Thailand & & & & \\
\hline
\end{tabular}




\begin{tabular}{|lcrrrc|}
\hline Characteristics & Asia & Europe & America & Australia & Total \\
\hline Expatriate & $30.9 \%$ & $35.2 \%$ & $39.4 \%$ & $17.8 \%$ & $31.5 \%$ \\
\hline $\begin{array}{l}\text { Fly in to receive medical } \\
\text { services }\end{array}$ & $30.9 \%$ & $7.1 \%$ & $13.1 \%$ & $46.9 \%$ & $21.3 \%$ \\
\hline Vacation & $22.7 \%$ & $46.8 \%$ & $32.1 \%$ & $30.8 \%$ & $35.9 \%$ \\
\hline Business & $12.8 \%$ & $8.1 \%$ & $11.1 \%$ & $3.7 \%$ & $8.7 \%$ \\
\hline Other & $2.7 \%$ & $2.8 \%$ & $4.3 \%$ & $0.7 \%$ & $2.6 \%$ \\
\hline Financial responsibility & & & & & \\
\hline Self-pay & $58.6 \%$ & $47.0 \%$ & $59.3 \%$ & $78.3 \%$ & $58.0 \%$ \\
\hline Insurance coverage & $28.3 \%$ & $47.3 \%$ & $34.3 \%$ & $19.3 \%$ & $35.6 \%$ \\
\hline $\begin{array}{l}\text { Reimbursement } \\
\text { from company }\end{array}$ & $13.1 \%$ & $5.6 \%$ & $6.5 \%$ & $2.3 \%$ & $6.4 \%$ \\
\hline
\end{tabular}

\subsubsection{Exploratory factor analysis (assessment of the measures)}

The assessment and purification of scale items separated by continent were done in the following ways.

Firstly, an exploratory factor analysis was conducted to see whether the item scales were grouped. Principal axis analysis with oblimin rotation for factor analysis was used. The Eigenvalue equal to or more than 1 criterion was taken to determine the number of components to be extracted. Similarly, Kaiser-Meyer-Olkin values equal to and greater than 0.50 factor loading criteria were taken to determine the relevancy of data reduction and grouping items. Items that were poorly related to their hypothesized factors, as well as those associated with more than one factor, were deleted.

Secondly, using Cronbach's alpha estimates and item-to-total correlations, the reliabilities of items measuring each hypothesised factor were checked and those items that were unreliable were deleted. These steps were repeated until clean factors emerged. Results from these processes identified four groups of items for the service quality measurement model. Compared to the proposed conceptual framework, the dimensions of 'service facility', 'service personnel', 'service professional' and 'service product' remained, but 'service performance' was removed because some items were identified under another dimension. It was found that each continent identified a different service quality model. Two dimensions were identified in all groups, that is, 'service personnel' and 'service professional', but there were some differences in the identified items. The total of 48 items was reduced to $27-44$ items. A twodimension model with 44 items was identified for Australia; similarly for Europe, two dimensions with 44 items were found. America identified a three-dimension model with 27 items and an additional dimension - 'service product'. Lastly, the Asia service quality model was composed of four dimensions, including 36 items to which 'service product' and 'service facility' were added. All the four models with service dimensions identified items were further progressed by using structural equation models which could be specified to investigate measurement issues, to examine structural relationships among sets of variables or to accomplish both purposes simultaneously (Fornell \& Larcker, 1981).

\subsubsection{Measurement model of service quality}

A confirmatory factor analysis (CFA) was conducted in order to establish confidence in the measurement of the indicators. Each dimension was analysed separately. Based on the results of the CFA, the item loadings should be at least 0.5 but ideally 0.7 or higher; a higher number confirms being strongly related to their associated construct. Initial CFA indicated the possibility of improving goodness-of-fit statistics for the measurement model. After consideration of the modification indices, a number of items were eliminated from the reliability construct of each model. This process resulted in items with a two- to four-factor structure that was proposed by the previous step. 
The final CFA for the model of Australia confirmed two dimensions with 22 indicators, which included 11 under 'service personnel' (courtesy, empathy, 2 items of responsiveness, assurance, competency, inform on progress, problem-solving, equity and waiting time) and 11 indicators under 'service professional' (advanced technology, creditability, specialised service, quality certification, physician proficiency, 2 items of assurance, communication, ethical care, consistency and positive outcome).

The European model confirmed two dimensions with total 16 indicators, 11 indicators under 'service personnel' ( 2 items of courtesy, 3 items of responsiveness, 2 items of empathy, competency, problemsolving, equity, courtesy and accessibility) and 5 indicators under 'service professional' (specialised service, physician proficiency, 2 indicators of assurance and communication).

Three-dimension models with 17 items were confirmed for America; 'service personnel' contained 9 indicators ( 2 items of courtesy, 2 items of empathy, 3 items of responsiveness, assurance and competency), 5 indicators of 'service professional' (physician proficiency, assurance, communication, ethical care and positive outcome) and 3 indicators of 'service product' (advance technology, quality certification and physician proficiency).

The final model of Asia was composed of four dimensions with 20 indicators; 3 indicators of 'service personnel' ( 2 items of responsiveness and competency), 6 indicators of 'service professional' ( 2 items of assurance, communication, ethical care, positive outcome and reliability), 4 indicators of 'service product' (advance technology, advance medical equipment, variety of service and physician proficiency) and 7 indicators of 'service facility' (privacy, visually attractive, safety, 2 items of accessibility, timeliness and waiting time). The goodness-of-fit indices (GFIs) of the measurement model showed that the overall fit displayed an acceptable level, as suggested by Hair, Black, Bablin, and Anderson (2010). In this study, most variables had a factor loading higher than 0.70 and the 0.01 significance level as well. Thus, all variables were significantly related to their specified constructs, confirming the posited relationships among indicators and constructs. The overall measurement model was examined, including one exogenous construct (overall perceived service quality) and two to four latent path constructs (service personnel, service professional, service product and service facility).

The overall model indicates that the GFIs are within an acceptable level of fit in all the four groups, where $\mathrm{x} 2 / \mathrm{df}$ is between 2 and 5 with a significant p-value ,0.01, and other GFIs also showed an excellent level of fit, for example, GFI close to 1; Australia $=0.911$, Europe $=0.950$, America $=0.926$ and Asia $=0.919$. The other model fit was evaluated using the Comparative Fit Index, the Normed Fit Index and the root-mean-square error of approximation on the basis of the fit criteria established in a prior service study (Hair et al., 2010). A summary is given in Tables 2 and 3. 
Table 2: Results of confirmatory factor analysis (CFA)

\begin{tabular}{|c|c|c|c|c|c|c|c|c|c|c|c|c|c|c|c|c|}
\hline & \multicolumn{4}{|c|}{ Australia } & \multicolumn{4}{|c|}{ Europe } & \multicolumn{4}{|c|}{ America } & \multicolumn{4}{|c|}{ Asia } \\
\hline & $\begin{array}{c}\text { Factor } \\
\text { Loadin } \\
\mathrm{g} \\
\end{array}$ & S.E & $\begin{array}{c}\mathrm{t}- \\
\text { value }\end{array}$ & $r^{2}$ & $\begin{array}{c}\text { Factor } \\
\text { Loadin } \\
\mathrm{g} \\
\end{array}$ & S.E & $\begin{array}{c}\mathrm{t}- \\
\text { value }\end{array}$ & $\mathrm{r}^{2}$ & $\begin{array}{c}\text { Factor } \\
\text { Loadin } \\
\mathrm{g} \\
\end{array}$ & S.E & $\begin{array}{c}\mathrm{t}- \\
\text { value }\end{array}$ & $r^{2}$ & $\begin{array}{c}\text { Factor } \\
\text { Loadin } \\
\mathrm{g} \\
\end{array}$ & S.E & $\begin{array}{c}\mathrm{t}- \\
\text { value }\end{array}$ & $\mathrm{r}^{2}$ \\
\hline \multicolumn{17}{|c|}{ Service Personnel } \\
\hline Cour1 & 1.03 & 0.04 & 26.21 & 0.76 & 1.00 & - & $\mathrm{a}$ & 0.67 & 1.00 & - & A & 0.62 & - & - & - & - \\
\hline Emp2 & 1.00 & - & A & 0.76 & - & - & - & - & 1.05 & 0.05 & 19.47 & 0.72 & - & - & - & - \\
\hline Resp2 & 1.04 & 0.03 & 34.31 & 0.82 & 1.07 & 0.03 & 33.63 & 0.78 & 1.08 & 0.05 & 20.43 & 0.77 & 1.00 & - & $\mathrm{a}$ & 0.76 \\
\hline Resp4 & 1.00 & 0.04 & 26.88 & 0.78 & 1.06 & 0.03 & 33.05 & 0.77 & 1.09 & 0.05 & 20.94 & 0.80 & - & - & - & - \\
\hline Emp4 & 1.05 & 0.04 & 27.86 & 0.81 & 1.08 & 0.03 & 34.01 & 0.79 & 1.10 & 0.05 & 20.86 & 0.79 & - & - & - & - \\
\hline Ass 3 & 1.03 & 0.04 & 28.23 & 0.82 & - & - & - & - & 1.06 & 0.04 & 24.01 & 0.70 & - & - & - & - \\
\hline Comp2 & 1.05 & 0.04 & 28.57 & 0.83 & 1.02 & 0.03 & 30.92 & 0.70 & 1.01 & 0.05 & 20.76 & 0.66 & 0.99 & 0.04 & 24.93 & 0.74 \\
\hline Prob & 1.06 & 0.04 & 27.29 & 0.79 & 1.06 & 0.03 & 33.14 & 0.77 & - & - & - & - & - & - & - & - \\
\hline Inf & 0.99 & 0.04 & 24.95 & 0.72 & - & - & - & - & - & - & - & - & - & - & - & - \\
\hline Equi & 1.08 & 0.04 & 29.71 & 0.85 & 1.05 & 0.03 & 32.15 & 0.74 & - & - & - & - & - & - & - & - \\
\hline Wait & 0.99 & 0.04 & 22.67 & 0.65 & - & - & - & - & - & - & - & - & - & - & - & - \\
\hline Resp3 & - & - & - & - & 1.07 & 0.03 & 34.32 & 0.80 & 1.11 & 0.05 & 21.39 & 0.82 & 1.00 & 0.04 & 26.87 & 0.80 \\
\hline Emp5 & - & - & - & - & 1.37 & 0.05 & 30.07 & 0.68 & - & - & - & - & - & - & - & - \\
\hline Cour2 & - & - & - & - & 1.06 & 0.03 & 33.79 & 0.79 & 1.06 & 0.05 & 19.94 & 0.74 & - & - & - & - \\
\hline Acc2 & - & - & - & - & 1.23 & 0.04 & 28.94 & 0.58 & - & - & - & - & - & - & - & - \\
\hline \multicolumn{17}{|c|}{ Service Professional } \\
\hline Adv1 & 1.00 & - & A & 0.62 & - & - & - & - & - & - & - & - & - & - & - & - \\
\hline Cred & 0.91 & 0.06 & 16.70 & 0.52 & - & - & - & - & - & - & - & - & - & - & - & - \\
\hline Spec & 0.98 & 0.05 & 18.35 & 0.60 & 1.00 & - & $\mathrm{a}$ & 0.55 & - & - & - & - & - & - & - & - \\
\hline Qual & 1.67 & 0.08 & 20.95 & 0.59 & - & - & - & - & - & - & - & - & - & - & - & - \\
\hline PP2 & 1.07 & 0.05 & 20.82 & 0.73 & 1.13 & 0.04 & 26.09 & 0.68 & 1.00 & - & $\mathrm{a}$ & 0.59 & - & - & - & - \\
\hline Ass 1 & 1.08 & 0.05 & 20.82 & 0.73 & 1.15 & 0.05 & 24.86 & 0.72 & - & - & - & - & 1.00 & - & $\mathrm{a}$ & 0.67 \\
\hline Ass2 & 1.02 & 0.05 & 20.24 & 0.70 & 0.58 & 0.03 & 21.24 & 0.54 & 1.15 & 0.06 & 19.23 & 0.77 & 1.02 & 0.05 & 21.72 & 0.73 \\
\hline Comm1 & 1.05 & 0.05 & 20.04 & 0.69 & 1.09 & 0.05 & 24.18 & 0.69 & 1.10 & 0.06 & 18.22 & 0.71 & 1.07 & 0.05 & 22.66 & 0.77 \\
\hline Eth & 1.06 & 0.05 & 20.49 & 0.71 & - & - & - & - & 1.16 & 0.06 & 19.30 & 0.78 & 1.07 & 0.05 & 22.83 & 0.77 \\
\hline Cons & 1.01 & 0.05 & 19.37 & 0.66 & - & - & - & - & - & - & - & - & - & - & - & - \\
\hline Pos & 0.99 & 0.05 & 19.54 & 0.66 & - & - & - & - & 1.08 & 0.06 & 17.68 & 0.67 & 1.07 & 0.05 & 22.64 & 0.76 \\
\hline Reli1 & - & - & - & - & - & - & - & - & - & - & - & - & 1.07 & 0.05 & 21.87 & 0.73 \\
\hline
\end{tabular}


Table 2: Result of confirmatory factor analysis (continued)

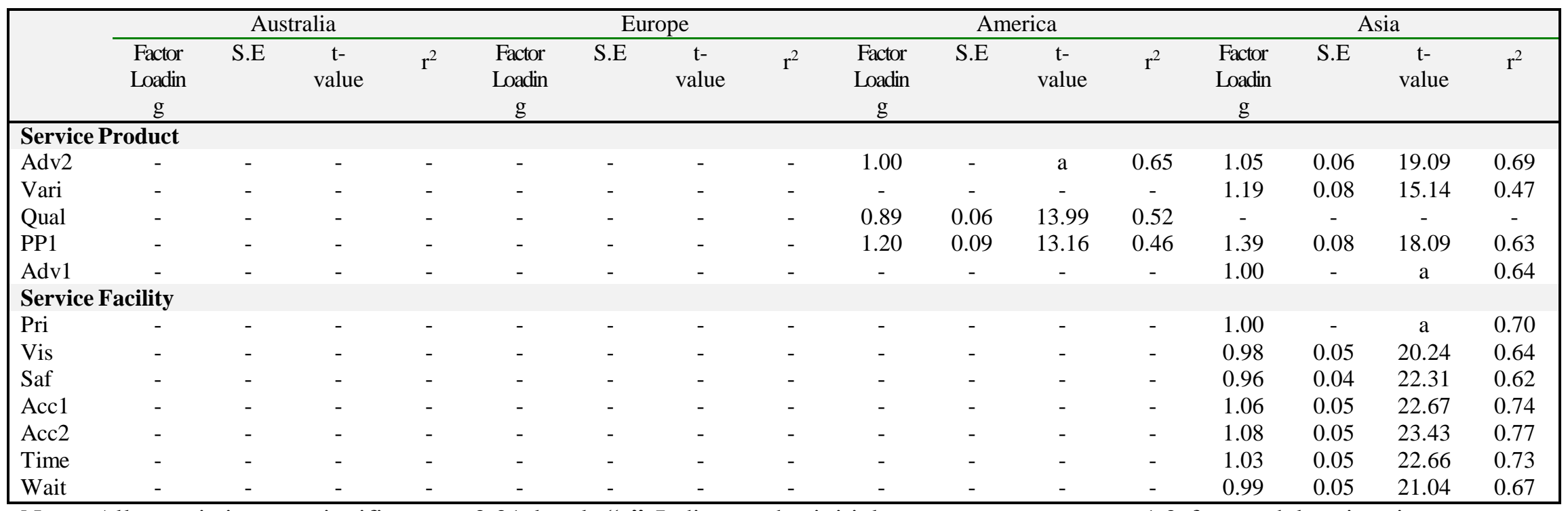

Note: All t-statistics are significant at 0.01 level; "a" Indicates the initial parameter was set to 1.0 for model estimation purposes (normally over-identifying first-order CFA modelling is conducted by fixing the loading of one indicator for each latent factor to equal 1)

Table 3. Goodness-of-fit statistics for measurement model of hospital service quality

\begin{tabular}{|c|c|c|c|c|c|c|c|c|c|}
\hline & $x^{2}$ & $\mathrm{df}$ & $x^{2} / d f$ & GFI & AGFI & CFI & RFI & NFI & RMSEA \\
\hline Criteria & - & - & $2-5$ & Close to 1 & Close to1 & Close to 1 & Close to 1 & Close to 1 & $<0.07$ \\
\hline Australia & 547.546 & 240 & 2.281 & .911 & .903 & .976 & .952 & .959 & .053 \\
\hline Europe & 408.685 & 126 & 3.244 & .950 & .933 & .984 & .972 & .977 & .050 \\
\hline America & 306.231 & 144 & 2.127 & .926 & .903 & .978 & .953 & .960 & .053 \\
\hline Asia & 446.061 & 200 & 2.230 & .919 & .897 & .975 & .949 & .956 & .053 \\
\hline
\end{tabular}

Note: $x^{2}=$ Chi-square; GFI = Goodness-of-fit index; AGFI= Adjusted goodness-of-fit index; CFI = Comparative fit index; RFI =

Relative fit index; NFI = Normed fit index; RMSEA = Root mean square error of approximation

Source: Hair et al. (2010) 


\subsection{Structure model}

Within the overall model, the estimates of the structural coefficients provide the basis for testing with one exogenous variable (i.e. overall perceived service quality) and four variables (personnel, professional, product and facility). Therefore, assessment of the structural model involves estimating the path loadings and the R2 values. Path loadings indicate the strengths of the relationships between latent variables, while R2 indicates the amount of variance explained by the exogenous variable. Table 4 reports the measured effects of all relationships. As indicated by the path coefficients, the associated significance levels and the influence of overall perceived service quality on each dimensions, Australia, service personnel $(b=$ 0.932), service professional $(b=0.906)$; Europe, service personnel $(b=0.976)$, service professional $(b=$ $0.818)$; America, service personnel $(\mathrm{b}=0.951)$, service professional $(\mathrm{b}=0.883)$, service product $(\mathrm{b}=$ 0.813); Asia service personnel $(b=0.96)$, service professional $(b=0.88)$, service product $(b=0.83)$, service facility $(b=0.93)$ and all of them were found to be significant at the 0.001 level.

For hypothesis testing, the results show that hospital service quality has a significant relationship with patient satisfaction in all groups; Australia $(b=0.96)$, Europe $(b=0.99)$, America $(b=0.97)$ and Asia $(b$ = 0.97); thus, $\mathrm{H} 1$ is supported. Meanwhile, $\mathrm{H} 2$ states that patient satisfaction has a significant relationship with behavioural intention. The results show that $\mathrm{H} 2$ is supported in all groups: Australia $(\mathrm{b}=0.94)$, Europe $(b=0.89)$, America $(b=0.81)$ and Asia $(b=0.77)$.

Table 4: Structural model of hospital service quality

\begin{tabular}{lcccccccc}
\hline & \multicolumn{2}{c}{ Australia } & \multicolumn{2}{c}{ Europe } & \multicolumn{2}{c}{ America } & \multicolumn{2}{c}{ Asia } \\
\cline { 2 - 8 } & $\beta$ & $\rho$ & $\beta$ & $\rho$ & $\beta$ & $\rho$ & $\beta$ & $\rho$ \\
Service Quality $\rightarrow$ Satisfaction & .956 & $* * *$ & .990 & $* * *$ & .971 & $* * *$ & .970 & $* * *$ \\
Satisfaction $\rightarrow$ BI & .939 & $* * *$ & .887 & $* * *$ & .814 & $* * *$ & .867 & $* * *$ \\
Service Personnel $\rightarrow$ SQ & .932 & $* * *$ & .976 & $* * *$ & .951 & $* * *$ & .960 & $* * *$ \\
Service Professional $\rightarrow$ SQ & .906 & $* * *$ & .818 & $* * *$ & .883 & $* * *$ & .882 & $* * *$ \\
Service Product $\rightarrow$ SQ & - & - & - & - & .813 & $* * *$ & .829 & $* * *$ \\
Service Facility $\rightarrow$ SQ & - & - & - & - & - & - & .928 & $* * *$ \\
\hline
\end{tabular}

Note: The probability of obtaining a critical ratio as large as 18.647 in absolute value is less than 0.001. In other words, the regression weight for service quality in the prediction of F2 is level (two-tailed), significantly different from zero at the 0.001 level (Schumacker and Lomax, 2004) 
5. Conclusions, limitations and future research directions.

The purpose of this study was to investigate hospital service quality and its effect on patient satisfaction and behavioural intention. Structural equation modeling (SEM) is a tool enabling researchers to go beyond factor analysis into the arena of determining whether one set of unobserved constructs (dimensions) can cause (be seen to be likely to determine) another set of dimensions. In healthcare studies, it is often the case that the variables under study cannot be directly observed or measured (e.g. motivation, satisfaction, importance and perception). The SEM approach was used to test the construct's framework between hospital service quality, patient satisfaction and behavioural intention.

The results confirmed both hypotheses that perceived service quality has a significant relationship with patient satisfaction and patient satisfaction has a significant relationship with behavioural intention. Moreover, service quality dimensions identified a significant relationship with hospital service quality even though the quality dimensions were found to have a distinct construct in four continents. This suggested that patients evaluated the service quality on two to five basic dimensions, but that they also viewed overall service quality as a higher order factor that captured a meaning common to all dimensions.

The findings of this study indicate that the establishment of higher levels of hospital service quality will lead patients to have a high level of satisfaction. In addition, to achieve competitive advantage, the hospital management needs to be aware of the relative importance of each of the service quality dimensions in the satisfaction of patients, which varies across different hospital utilisation groups, and use this in strategic considerations. It is, therefore, important that 'service personnel' and 'service professional' were found to be the significant dimensions across the four groups. Service behaviour in providing a service should, then, be considered to be a key strategic improvement to provide a better competitive service delivery in a professional manner. Patients' perceived healthcare service quality has changed over time due to new technology, innovation and innovation in treatment. The dynamic nature of service quality suggests that hospital managers must track patients' perception over time and align product and promotional strategies associated with these changing views.

Although this study has been carefully conducted, some limitations should be mentioned. Firstly, the survey was limited to the context of examining those patients' perception of service quality who had received service outside their own country of residence. Compared to a resident patient who is more familiar with the hospital and system, a travelling patient leaving the hospital after a brief visit may have gained limited experience of the hospital environment as well as with physicians and non-physician care providers. Therefore, the key dimensions that underlie the service quality impressions may differ between those groups. Secondly, the type of service received based on the severity of illness was not considered in this study. The severity of illness may draw different conclusions regarding healthcare service quality. Given these limitations, this study encourages other researchers to conduct further research based on the findings of this study.

\section{References}

Aagja, J. P., \& Garg, R. (2010). Measuring perceived service quality for public hospitals (PubHosQual) in the Indian context. International Journal of Pharmaceutical and Healthcare Marketing, 4(1), 60- 83.

Alrubaiee, L. (2011). The Mediating Effect of Patient Satisfaction in the Patients' Perceptions of Healthcare Quality - Patient Trust Relationship. International Journal of Marketing Studies, 3(1), 103-127.

Babakus, E., \& Boller, G. W. (1992). An Empirical Assessment of the SERVQUAL Scale. Journal of Business Research 24, 253-268.

Babakus, E., \& Mangold, W. G. (1992). Adapting the SERVQUAL Scale to Hospital Services: An 
Empirical Investigation. Health Services Research, 26(6).

Bitner, M. J. (1990). Evaluating Service Encounters: The Effects of Physical Surroundings and Employee Responses. Journal of Marketing, 54, 69-82.

Bowers, M. R., Swan, J. E., \& Koehler, W. F. (1994). What attributes determine quality and satisfaction with health care delivery? Health Care Management Review, 19(4), 49-55.

Brady, M. K., \& Cronin, J. J. (2001). Some New Thoughts on Conceptualizing Perceived Service Quality: A Hierarchical Approach. Journal of Marketing, 65, 34-49.

Calnan, M. (1988). Toward a conceptual framework of lay evaluation of healthcare. Soc.Sci.Med, 27(927933).

Carman, J. M. (2000). Patient perceptions of service quality: combining the dimensions Journal of Services Marketing, 14(4), 337-352.

Chahal, H., \& Kumari, N. (2010). Development of multidimensional scale for healthcare service quality (HCSQ) in Indian context. Journal of Indian Business Research, 2(4), 230-255.

Chen, C. C., \& Cheng, S. H. (2010). Hospital competition and patient-perceived quality of care: Evidence from a single-payer system in Taiwan. Health Policy, 98(1), 65-73.

Choi, K.-S., Cho, W.-H., Lee, S., Lee, H., \& Kim, C. (2004). The relationships among quality, value, satisfaction and behavioral intention in health care provider choice: A South Korean study. Journal of Business Research 57, 913-921.

Choi, K.-S., Lee, H., Kim, C., \& Lee, S. (2005). The service quality dimensions and patient satisfaction relationships in South Korea: comparisons across gender, age and types of service. Journal of Services Marketing, 19(3), 140-149.

Cronin, J. J., \& Taylor, S. A. (1992). Measuring Service Quality: A Reexamination and Extension. Journal of Marketing, 56, 55-68.

Cronin, J. J., Brady, M. K., \& Hult, G. T. M. (2000). Assessing the Effects of Quality, Value, and Customer Satisfaction on Consumer Behavioral Intentions in Service Environments. Journal of Retailing, 76(2), 193-218.

D'Souza, S. C., \& Sequeira, A. H. (2012). Measuring the customer-perceived service quality in health care organization: a case study. Journal of Health Management, 14(1), 27-41.

Donabedian, A. (1978). The Quality of Medical Care. Science, 200(4344), 856-864.

Donabedian, A. (1988). The Quality of Care How Can It Be Assessed? JAMA, 260(12), 1743-1748.

Eleuch, A. e. K. (2011). Healthcare service quality perception in Japan. International Journal of Health Care Quality Assurance, 24(6), 417-429.

Fornell, C., \& Larcker, D. F. (1981). Evaluating structural equation models with unobservable variables and measurement error. Journal of Marketing Research, 18(1), 39-50.

Grönroos, C. (1984). A Service Quality Model and its Marketing Implications. European Journal of Marketing 18(4), 36-44.

Hair, J. F., Black, W. C., Bablin, B. J., \& Anderson, R. E. (2010), Multivariate Data Analysis, 7th ed., Pearson Education, Upper Saddle River, NJ. 
Hasin, M. A. A., Seeluangsawat, R., \& M. A. Shareef. (2001). Statistical measures of customer satisfaction health care quality assurance: a case study. International Journal of Health Care Quality Assurance, 14(1), 6-14.

Headley, D. E., \& Miller, S. J. (1993). Measuring Service Quality and its Relationship to Future Consumer Behavior. Journal of Health Care Marketing, 13(4), 32-41.

Herrick, D. M. (2007). "Medical tourism :global competition in health care." National Center for Policy Analysis NCPA Policy Report (304): 1-35.

Kara, A., Lonial, S., Tarim, M., \& Zaim, S. (2005). A paradox of service quality in Turkey. European Business Review, 17(1), 5-20.

Lee, H., Delene, L. M., Bunda, M. A., \& Kim, C. (2000). Methods of Measuring Health-Care Service Quality. Journal of Business Research, 48, 233-246.

Lim, P. C., \& Tang, N. K. H. (2000). A study of patients' expectations and satisfaction in Singapore hospital. International Journal of Health Care Quality Assurance, 13(7), 290-299.

McAlexander, J. H., Kaldenberg, D. O., \& Koenig, H. F. (1994). Service Quality Measurement. Journal of Health Care Marketing, 14(3), 34-40.

Nekoei-Moghadam, M., \& Amiresmaili, M. (2011). Hospital services quality assessment: Hospitals of Kerman University of Medical Sciences, as a tangible example of a developing country. International Journal of Health Care Quality Assurance, 24(1), 57-66.

National Statistical Office of Thailand

Pai, Y. P., \& Chary, S. T. (2013). Dimensions of hospital service quality: a critical review: perspective of patients from global studies. International Journal of Health Care Quality Assurance, 26(4), 308-340.

Parasuraman, A., Zeithaml, V. A., \& Berry, L. L. (1988). SERVQUAL : A multiple-item scale for measuring consumer perceptions of service quality. Journal of Retailing, 64(12-40).

Peyrot, M., Philip D, C., \& Schnapf, D. (1993). Consumer Satisfaction and Perceived Quality of Outpatient Health Services. Journal of HealthcareCare Marketing, Winter, 24-33.

Pocock, N. S., \& Phua, K. H. (2011). Medical tourism and policy implications for health systems: a conceptual framework from a comparative study of Thailand, Singapore and Malaysia. Global Health, 7, 12.

Reidenbach, R. E., \& Sandifer-Smallwood, B. (1990). Exploring Perceptions of Hospital Operations by a Modified SERVQUAL Approach. Journal of Health Care Marketing, 10(4), 47-55.

Rose, R. C., Uli, F., Abdul, M., \& Ng, K. L. (2004). Hospital service quality: a managerial challenge. International Journal of Health Care Quality Assurance, 17(3), 146-159.

Schumacker, R. E., \& Lomax, R. G. (2004). A beginner's guide to structure equation modeling. Lawrence Erlbaum Associates, New Jersey, London.

Suki, N. M., Lian, J. C. C., \& Suki, N. M. (2011). Do patients' perceptions exceed their expectations in private healthcare settings? International Journal of Health Care Quality Assurance, 24(1), 4256.

Untachai, S. (2013). Modeling service quality in hospital as a second order factor, Thailand. Procedia Social and Behavioral Sciences, 88, 118-133.

Zeithaml, V. A., Berry, L. L., \& Parasuraman, A. (1996). The Behavioral Consequences of Service Quality. Journal of Marketing, 60, 31-46.

Zeithaml, V. A., Parasuraman, A., \& Berry, L. L. (1985). Problems and strategies in services marketing. Journal of Marketing, 49(Spring), 33-46 